\title{
Suicide in recently released prisoners: a population-based cohort study
}

Daniel Pratt, Mary Piper, Louis Appleby, Roger Webb, Jenny Shaw

\begin{abstract}
Summary
Background Several studies have been undertaken on suicide in custody, but few on suicide after the release from prison. We undertook a population-based cohort study to investigate suicide rates in recently released prisoners in England and Wales.
\end{abstract}

Methods We used the database of the National Confidential Inquiry into Suicide and Homicide by People with Mental Illness for England and Wales to identify all individuals who died by suicide or who received an open verdict at the coroner's inquest between 2000 and 2002. These records were linked to a Home Office register to identify all such deaths in people within 1 year of release from prison in England and Wales. We compared suicide rates per 100000 person-years in these released prisoners with rates in the general population by using the indirectly agestandardised mortality ratio.

Findings We identified 382 suicides occurring in 244988 individuals within 1 year of release from prison; a suicide rate of 156 per 100000 person-years. 79 (21\%) suicides occurred within the first 28 days after release. In all age groups, suicide rates were higher in recently released prisoners than in the general population. The overall age-standardised mortality ratio for recently released prisoners was $8 \cdot 3(95 \%$ CI $7 \cdot 5-9 \cdot 3)$ for men and $35 \cdot 8(25 \cdot 4-50 \cdot 2)$ for women.

Interpretation Recently released prisoners are at a much greater risk of suicide than the general population, especially in the first few weeks after release. The risk of suicide in recently released prisoners is approaching that seen in discharged psychiatric patients. A shared responsibility lies with the prison, probation, health, and social services to develop more collaborative practices in providing services for this high-risk group.

\section{Introduction}

Several studies have examined the risk factors for suicide in custody, ${ }^{1-5}$ but little is known about the risk of suicide after release from prison..$^{6-8}$ A study in Finland ${ }^{7}$ showed that the suicide rate in people within 1 year of release from prison was almost three times the rate in the general population. A study in England and Wales ${ }^{8}$ showed that male offenders under criminal justice community supervision were at least ten times more likely to die by suicide than men in the general population. This study was a national study, but included only prisoners released under the supervision of probation, thus excluding more than half of all released prisoners. Here, we report data for a comprehensive 3-year national sample of self-inflicted death within 12 months of release from prison in England and Wales.

\section{Methods}

Study cohort

This study was approved by the multicentre research ethics committee of the Thames Valley National Health Service (NHS), Reading, UK. Information on suicides was taken from the database of the National Confidential Inquiry into Suicide and Homicide by People with Mental Illness, ${ }^{9}$ which has records of individuals in England and Wales who receive a verdict of suicide or an open verdict at coroner's inquest. This information was obtained from the Office for National Statistics for England and Wales. Most open verdicts are conventionally defined as suicide. ${ }^{10}$
Therefore, we have classified suicide and open verdicts as suicides in this Article. From the National Confidential Inquiry database, we identified all suicides that took place between Jan 1, 2000, and Dec 31, 2002.

Person-identifiable data were obtained from the discharge extract files of the Inmate Information System (IIS), a Home Office database containing details of all sentenced and remanded prisoners released from prison in England and Wales. Using names and dates of birth, we linked the National Confidential Inquiry list of suicides with the IIS Discharge Extract file of prisoners whose most recent release from prison was between Jan 1, 1999, and Dec 31, 2002. Cases were selected from the linked records if the person's date of death occurred within 12 months of their date of release from prison.

Study individuals were then cross-referenced against a database recording information on all self-inflicted deaths in prisons in England and Wales. ${ }^{5}$ These deaths had been classified by prison service staff as suicides and recorded on a prison database before inquest. We found that 13 self-inflicted deaths previously identified as cases actually took place on the date of release, but while the prisoner was still in prison. These 13 deaths were excluded from this study.

\section{Statistical analysis}

We calculated suicide in the general population by using the estimated aggregate national population base for every year in 2000-02 combined as the denominator. ${ }^{11}$
Lancet 2006; 368: 119-23

See Editorial page 92

Centre for Suicide Prevention University of Manchester, Manchester M13 9PL, UK (D Pratt MSc, Prof L Appleby FRCPsych, RWebb MSc, Prof J Shaw MRCPsych); and Department of Health, London, UK (M Piper FRCP)

Correspondence to: Dr Jenny Shaw jennifer.j.shaw@manchester. ac.uk 


\begin{tabular}{|c|c|c|c|c|c|c|c|}
\hline & \multicolumn{3}{|c|}{ General population* $^{*}$} & \multicolumn{3}{|c|}{ Recently released prisoner population* } & \multirow[t]{2}{*}{ Rate ratio $(95 \% \mathrm{Cl})$} \\
\hline & $\begin{array}{l}\text { Number of } \\
\text { person-years }\end{array}$ & $\begin{array}{l}\text { Number of } \\
\text { suicides }\end{array}$ & $\begin{array}{l}\text { Rate (per } 100000 \\
\text { person-years) }\end{array}$ & $\begin{array}{l}\text { Number of } \\
\text { person-years }\end{array}$ & $\begin{array}{l}\text { Number of } \\
\text { suicides }\end{array}$ & $\begin{array}{l}\text { Rate (per } 100000 \\
\text { person-years) }\end{array}$ & \\
\hline \multicolumn{8}{|l|}{ Women } \\
\hline $18-20$ years & 2826200 & 92 & $3 \cdot 3$ & 2522 & 5 & $198 \cdot 3$ & $60 \cdot 9(19 \cdot 3-147 \cdot 3)$ \\
\hline 21-24 years & 3762700 & 159 & $4 \cdot 2$ & 4049 & 7 & $172 \cdot 9$ & $40 \cdot 9(16 \cdot 2-86 \cdot 3)$ \\
\hline $25-29$ years & 5228600 & 277 & $5 \cdot 3$ & 4359 & 5 & $114 \cdot 7$ & $21 \cdot 7(7 \cdot 0-51 \cdot 1)$ \\
\hline 30-39 years & 12331200 & 709 & 5.8 & 5696 & 9 & $158 \cdot 0$ & $27 \cdot 5(12 \cdot 5-52 \cdot 5)$ \\
\hline $40-49$ years & 10587700 & 638 & $6 \cdot 0$ & 1803 & 7 & $388 \cdot 2$ & $64 \cdot 4(25 \cdot 8-133 \cdot 5)$ \\
\hline$\geq 50$ years & 28346600 & 1693 & $6 \cdot 0$ & 513 & 1 & 194.9 & $32 \cdot 6(0 \cdot 8-182 \cdot 1)$ \\
\hline All women $\geq 18$ years & 63083000 & 3568 & $5 \cdot 7$ & 18942 & 34 & $179 \cdot 5$ & $35 \cdot 8(25 \cdot 4-50 \cdot 2) \dagger$ \\
\hline \multicolumn{8}{|l|}{ Men } \\
\hline $18-20$ years & 2902100 & 380 & $13 \cdot 1$ & 38346 & 28 & 73.0 & $5 \cdot 6(3 \cdot 7-8 \cdot 2)$ \\
\hline 21-24 years & 3762900 & 614 & $16 \cdot 3$ & 48476 & 42 & 86.6 & $5 \cdot 3(3 \cdot 8-7 \cdot 3)$ \\
\hline 25-29years & 5211900 & 1058 & $20 \cdot 3$ & 47767 & 75 & $157 \cdot 0$ & $7 \cdot 7(6 \cdot 1-9 \cdot 9)$ \\
\hline 30-39 years & 12175500 & 2683 & $22 \cdot 0$ & 61336 & 124 & $202 \cdot 2$ & $9 \cdot 2(7 \cdot 7-11 \cdot 1)$ \\
\hline $40-49$ years & 10438100 & 2181 & $20 \cdot 9$ & 20718 & 57 & $275 \cdot 1$ & $13 \cdot 2(9 \cdot 9-17 \cdot 1)$ \\
\hline$\geq 50$ years & 24069500 & 3613 & $15 \cdot 0$ & 9403 & 22 & 234.0 & $15 \cdot 6(9 \cdot 8-23 \cdot 6)$ \\
\hline All men $\geq 18$ years & 58560000 & 10529 & $18 \cdot 0$ & 226046 & 348 & $154 \cdot 0$ & $8 \cdot 3(7 \cdot 5-9 \cdot 3) \dagger$ \\
\hline Overall ratio & .. & .. & .. & .. & .. & .. & $4 \cdot 3(2 \cdot 9-6 \cdot 1) \ddagger$ \\
\hline \multicolumn{8}{|l|}{ All individuals } \\
\hline$\geq 18$ years & 121643000 & 14097 & 11.6 & 244988 & 382 & $155 \cdot 9$ & $13 \cdot 5(12 \cdot 2-14 \cdot 9)$ \\
\hline
\end{tabular}

Suicide for recently released prisoners was also calculated by use of the aggregate yearly population of released prisoners for 2000-02, with the person-years indicating 1-year postrelease information. These denominators were

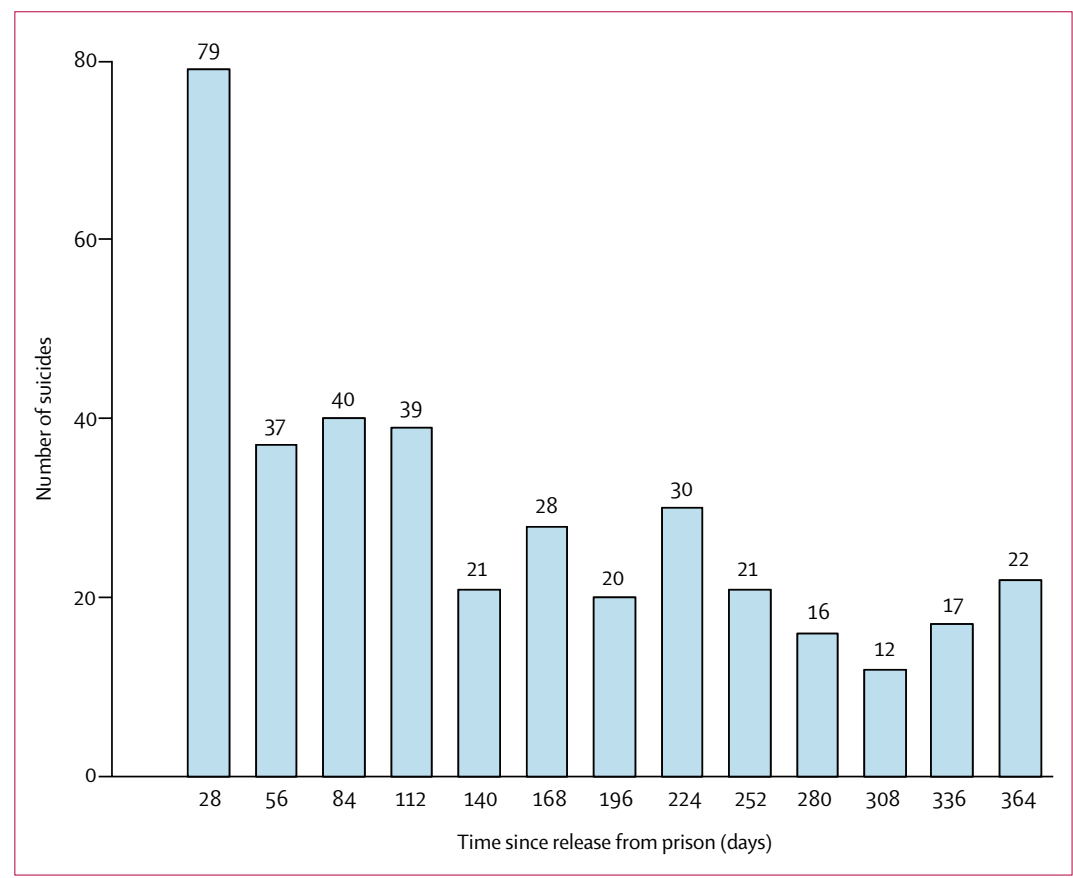

Figure 1: Frequency of suicides during 1 year of release from prison used as proxies for the person-years at risk in the study and general populations. Standardised mortality ratios were defined as the ratio of the observed versus the expected number of suicides, with adjustment for differences in age distribution between the released prisoners and general populations. ${ }^{12,13}$ This indirect method of standardisation is robust if numbers of events per stratum are sparse in the study population. We used Poisson methods to calculate $95 \%$ CIs. Analyses were undertaken with STATA version 8.0.

\section{Role of the funding source}

The sponsor of the study had no role in study design, data collection, data analysis, data interpretation, or writing of the report. The corresponding author had full access to all the data in the study and had final responsibility for the decision to submit for publication.

\section{Results}

In 244988 released prisoners, we identified 382 suicides ( 34 women, 348 men) within 1 year of release. Suicides by recently released prisoners accounted for 3\% of the 14097 suicides occurring between 2000 and 2002, while released prisoners accounted for only $0.2 \%$ of the population (table). Figure 1 shows the distribution of these suicides, separated into 28-day periods over the year after release. $79(21 \%)$ suicides took place in the first 28 days after release, and 195 (51\%) within the first 4 months. 
The overall rate of suicide was 156 per 100000 personyears (table). The rate in recently released male prisoners was 154 deaths per 100000 person-years, which increased with age, with the highest rates in those aged $40-49$ years (275 per 100000 per year) and 50 years or older (234 per 100000 per year; table). The overall rate of suicide in recently released female prisoners was 180 per 100000 person-years, although age-specific trends were impossible to discern because of sparse data. In all age and sex groups, suicide was substantially higher in recently released prisoners than in the general population (table). We directly compared the suicide rate between male and female prisoners who were recently released, using a Poisson regression model adjusted for age. Suicide between recently released men and women did not differ significantly (women vs men: age-adjusted rate ratio $1 \cdot 14$ [95\% CI $0 \cdot 80-1 \cdot 62$ ], $\chi^{2}$ test, $\mathrm{p}=0.469)$, which contrasts with the three-fold increase in risk recorded for men compared with women in the general population.

According to standardised mortality ratios for recently released prisoners, men were eight times and women 36 times more likely to die by suicide within 1 year of release from prison than would be expected in their respective sex groups in the general population. The standardised mortality ratio for women was about four times greater than that for men. This finding indicates that a higher excess suicide risk was seen in female released prisoners than in women from the general population. We saw evidence of a highly significant linear trend in the age-specific rate ratios in recently released men $\left(\chi^{2}\right.$ test, $\left.d f=1, p<0 \cdot 0001\right)$, with a rate ratio of about 5 for men younger than 25 years rising to more than 15 in men aged 50 years and older (figure 2). Figure 3 shows the age-specific rate ratios for suicide risk in recently released women.

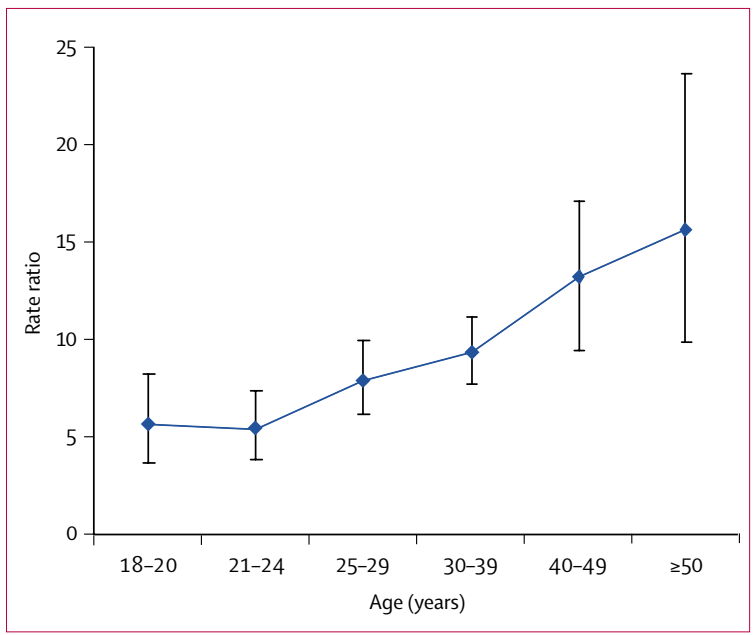

Figure 2: Age-specific rate ratios for suicide risk in recently released male prisoners compared with general population

Dots and error bars represent point estimates of the rate ratios and $95 \% \mathrm{Cls}$, respectively.

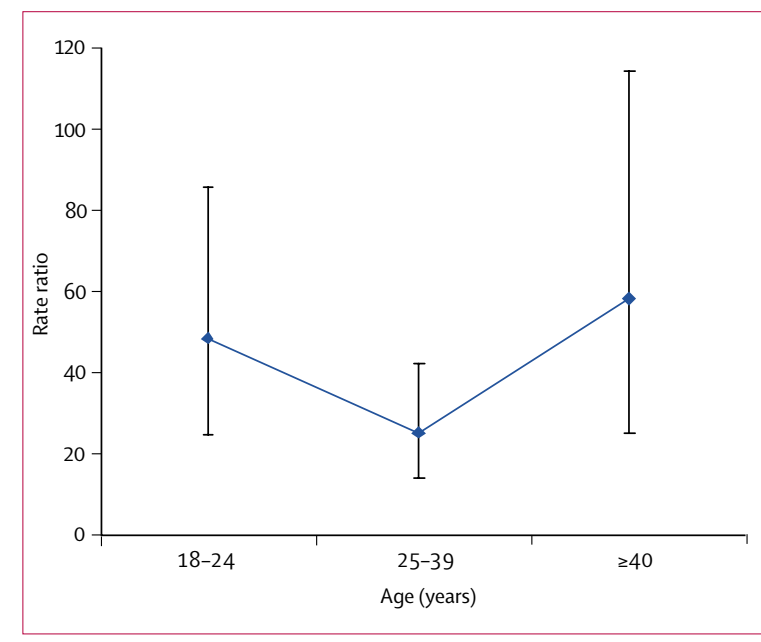

Figure 3: Age-specific rate ratios for suicide risk in recently released female prisoners compared with general population

Dots and error bars represent point estimates of the rate ratios and $95 \% \mathrm{Cls}$, respectively. Age categories have been collapsed for the figure.

\section{Discussion}

This study has shown that, during the first 12 months after release, prisoners in our analysis were at a much greater risk of suicide than the general population. Risk was particularly increased during the first 28 days, during which about a fifth of all suicides occurred. The risk was similar in men and women but, compared with the general population, the relative risk in women was substantially higher than in men. This result seems to support a previous finding that the rate of suicide for female offenders is similar to that for men, ${ }^{3}$ although female rates were based on small numbers of cases.

Few population-based studies have reported on suicides in released prisoners. Our main finding that offenders are at a raised risk of suicide after release from prison supports previous research. ${ }^{5,6}$ Furthermore, the high rate ratios of suicides in released prisoners compared with the general population accords with previous studies reporting an increase of 3-10 fold in the risk of suicide. ${ }^{7.8}$

The Inmate Information System used by this study is a database maintained by the Home Office and has been used by other research studies ${ }^{5,14}$ as well as to produce yearly prison statistics. ${ }^{15}$ Similarly, the database of suicides for England and Wales, to which we had access via the National Confidential Inquiry, has been extensively used to describe suicide in the general population and in people with mental illness. ${ }^{9}$ However, we have linked the two databases in our study.

Our sample size of suicides in male prisoners is adequate for drawing reliable conclusions, even when stratified by age. For suicides in female prisoners, a sample size of 34 was sufficient to calculate the standardised mortality ratio, but comparisons between different age groups were not reliable because of small numbers per stratum.

Although the standardised mortality ratios adjust for differences in age distributions between the study and 
general populations, prisoners have proportionally more risk factors for suicide, which include increased prevalence of mental illness, substance misuse, and socioeconomic deprivation..$^{16-20}$ Consequently, prisoners are already at a high risk of suicide and it is not surprising to find similar standardised mortality ratios for suicide in released and current prisoners. A study of suicide in male prisoners reported a standard mortality ratio of 5.1 (95\% CI $4 \cdot 8-5 \cdot 3) .{ }^{21}$ However, this finding does not explain the increased occurrence of suicide in the first 28 days after release.

A few of the deaths might have been drug-related. Drug misusers returning to their previous level of drug use after release from prison could have fatal consequences because of a loss of tolerance..$^{14}$ This event is unlikely to account for any of our recorded number of deaths in this study, since unintentional drug-related deaths are usually recorded as accidental deaths. ${ }^{22}$

The immediate postdischarge period is also a time of increased suicide risk in psychiatric patients after discharge from hospital, with a risk of suicide 50 times that expected in the general population..$^{23-25}$ The early stages after release are daunting and prisoners often face exclusion by the communities to which they are returning, as well as mutually re-enforcing barriers. ${ }^{26,27}$ For example, in 2002, about a third of prisoners were reported to have had no accommodation, almost half had lost contact with their families since entering prison, and three-quarters did not have paid employment to go to on release..$^{28}$ In the UK, prisoners sentenced to more than 14 days are eligible for a GBP $£ 46$ discharge grant, and an additional payment of up to $£ 50$ can be made to a legitimate housing provider before the prisoner's release, to secure accommodation, although these individuals often have to wait for several weeks before receiving any further benefits payments. ${ }^{28}$ Remanded prisoners do not receive any discharge grant despite the length of time in custody.

In addition to the social problems facing prisoners on release, many also have to cope with issues associated with mental-health problems. High psychiatric morbidity is well-known in prisoners, especially for women, ${ }^{16-20}$ and studies ${ }^{2,4}$ have shown mental illness to be a strong risk factor for prison suicide. Therefore, the rate of suicide in released prisoners would be expected to be higher than that in the general population. Furthermore, the raised prevalence of mental illness and personality disorder in female prisoners might have been indicated in the increased risk of postrelease suicide. ${ }^{29}$ Therefore, another possible explanation for high suicide risk in recently released prisoners could be the lack of adequate care and treatment given to prisoners for their suicidal ideation and associated mental-health problems, after release from prison.?

We recorded that older men were at a greater risk in this study, which is unexpected because aggressive impulsive traits, an important risk factor for suicide, can become less severe in offenders of older age. However, the challenges of reintegration into society after release from prison could affect older offenders more acutely than their younger counterparts. Also, suicides might have been more likely to take place in older individuals if mental illness was more prevalent in older offenders than in the general population. ${ }^{1}$ However, previous findings are contradictory and inconclusive, with older offenders over-represented in prison suicides in some studies, and under-represented in others. ${ }^{1,5}$ The problems of small sample sizes and the few comparable control groups make any interpretation difficult.

Our findings highlight the need for shared responsibility of the prison, probation, health, and community services including social services, housing, and benefits to provide good quality, integrated, mental-health care and social support for prisoners, both before and after release from prison. The effective resettlement or release of people from prison is thus vitally important. It should be a multidisciplinary function addressing the full range of resettlement needs, and recognising the multiple barriers that ex-prisoners face. Such needs include: the maintenance or rebuilding of family ties; referral and access to community-health care and treatment programmes, where appropriate; identification of housing needs and assistance to access accommodation, including supported accommodation; and training or employment opportunities. Individual care plans should be developed and monitored by multidisciplinary teams consisting of those professionals caring for the individual from both before and after release from prison. The team would be responsible for a structured assessment of prisoners' risk of suicide on their release and for ensuring that those prisoners identified as being at risk of suicide are provided with regular and routine contact with a community mental-health professional from the moment the individual leaves prison and during the first few months after release, depending on the needs of the individual.

Conflict of interest statement

L Appleby is National Director for Mental Health in England and overseas England's National Suicide Prevention Strategy. M Piper is Senior Public Health Adviser of Prison Health, UK Department of Health. The other authors declare that they have no conflict of interest.

\section{Contributors}

Daniel Pratt, Jenny Shaw, and Louis Appleby designed the study. Daniel Pratt obtained the data and, with assistance from Roger Webb, did the statistical analysis, supervised by Jenny Shaw. Daniel Pratt prepared the paper and all investigators contributed to the final manuscript.

\section{Acknowledgments}

The study was funded by the National Forensic Mental Health Research and Development Programme in the Department of Health, UK. We thank Nigel Hancock (Safer Custody Group, HM Prison Service) for his assistance in the collection of data.

References

1 Dooley E. Prison suicide in England and Wales 1972-87. Br J Psychiatry 1990; 156: 40-45.

2 Fruehwald S, Frottier P, Matschnig T, König F, Bauer P. Suicide in custody: a case-control study. Br J Psychiatry 2004; 185: 494-98.

3 Towl G, Snow L, McHugh M, eds. Suicide in prisons. Oxford: BPS Blackwell, 2002. 
4 Shaw J, Baker D, Hunt IM, Moloney A, Appleby L. Suicide by prisoners: a national clinical survey. Br J Psychiatry 2004; 184: 263-67.

5 Shaw J, Appleby L, Baker D. Safer prisons: a national study of prison suicides $1999-2000$ by the National Confidential Inquiry into Suicide and Homicide by People with Mental Illness. London: Department of Health, 2003.

6 Harding-Pink D. Mortality following release from prison. Med Sci Law 1990; 30: 12-16.

7 Joukamaa M. The mortality of released Finnish prisoners: a 7 year follow-up study of the WATTU project. Forensic Sci Int 1998; 96: 11-19.

8 Sattar G. The death of offenders in England and Wales. Crisis 2003; 24: 17-23.

9 Appleby L, Shaw J, Sherratt J, et al. Safety first: a 5-year report of the National Confidential Inquiry into Suicide and Homicide by People with Mental Illness. London: Department of Health, 2001.

10 Neeleman J, Wessely S. Changes in classification of suicide in England and Wales: time trends and association with coroners' professional background. Psychol Med 1997; 27: 467-72.

11 Office for National Statistics. Mortality Statistics-cause: series DH2 no 30. London: Office for National Statistics, 2004

12 Rothman KJ. Modern epidemiology. Boston: Little Brown, 1986.

13 Breslow N, Day N. Statistical methods in cancer research. Vol II: the design and analysis of cohort studies. Oxford: Oxford University Press, 1987.

14 Singleton N, Pendry E, Taylor C, Farrell M, Marsden J. Drug related mortality among newly-released offenders. London: Office for National Statistics, 2002.

15 Home Office. Prison Statistics: England and Wales 2002. London: Home Office, 2003.

16 Fazel S, Danesh J. Serious mental disorder in 23000 prisoners: a systematic review of 62 surveys. Lancet 2002; 359: 545-50.

17 Joukamaa M. Psychiatric morbidity among Finnish prisoners with special reference to socio-demographic factors: results of the Health Survey of Finnish Prisoners (Wattu Project). Forensic Sci Int 1995; 73: 85-91.
18 Brooke D, Taylor C, Gunn J, Maden A. Point prevalence of mental disorder in unconvicted male prisoners in England and Wales. BMJ 1996; 313: 1524-27.

19 Bland RC, Newman SC, Thompson AH, Dyck RJ. Psychiatric disorders in the population and in prisoners. Int J Law Psychiatry 1998; 21: 273-79.

20 Singleton N, Meltzer H, Gatword R, Coid J, Deasy D. Psychiatric morbidity among prisoners in England and Wales. London: Home Office, 1998

21 Fazel S, Benning R, Danesh J. Suicides in male prisoners in England and Wales, 1978-2003. Lancet 2005; 366: 1301-02.

22 Christophersen O, Rooney C, Kelly S. Drug-related mortality: methods and trends. Popul Trends 1998; 93: 29-37.

23 Goldacre M, Seagroatt V, Hawton K. Suicide after discharge from psychiatric in-patient care. Lancet 1993; 342: 283-86.

24 King EA, Baldwin DS, Sinclair JM, Baker NG, Campbell MJ, Thompson C. The Wessex recent in-patient suicide study I: casecontrol study of 234 recently discharged psychiatric patient suicides. Br J Psychiatry 2001; 178: 531-36.

25 Sohlman B, Lehtinen V. Mortality among discharged psychiatric patients in Finland. Acta Psychiatr Scand 1999; 99: 102-09.

26 Visher CA, Travis J. Transitions from prison to community: understanding individual pathways. Ann Rev Socio 2003; 29: 89-113. http://arjournals.annualreviews.org/doi/abs/10.1146/annurev. soc.29.010202.0959 (accessed June 21, 2006).

27 Fox A, Khan L, Briggs D, Rees-Jones N, Thompson Z, Owens J. Home Office on-line report 01/05-throughcare and aftercare: approaches and promising practice in service delivery for clients released from prison or leaving residential rehabilitation. London: Home Office, 2005.

28 Social Exclusion Unit. Reducing re-offending by ex-prisoners. London: Social Exclusion Unit, 2002.

29 Baxter D, Appleby L. A case register study of suicide risk in mental disorders. Br J Psychiatry 1999; 175: 322-26. 